\title{
Patterns Of Consumer Interest Across Developed And Emerging Markets
}

\author{
Gauri Kulkarni, Loyola University Maryland, USA
}

\begin{abstract}
In this study, we consider online search term volume as a measure of consumer interest and investigate the patterns of consumer interest across various international markets. Prior research has suggested that online search term volume, or the number of times a particular term is submitted to a search engine, can indicate aggregate or market-level interest in that term. As such, we consider the top terms in the US (most searched for) for one calendar year and look at the patterns of interest in those terms over time in the US, as well as in foreign developed and emerging markets. As globalization continues, consumers are likely to become more culturally integrated, particularly with the rapid spread of information. We explore one approach in measuring this phenomenon. We consider five dimensions of culture for eight foreign markets four developed and four emerging. We find high levels of cultural integration for terms related to technology products and social networks. Our results suggest implications for international marketing strategy.
\end{abstract}

Keywords: Online Search; Cultural Integration

\section{INTRODUCTION}

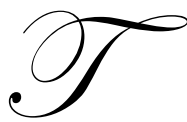

he rapid rise of global economies, markets, customers, and firms has resulted in the need for research on cross-cultural issues, particularly in business and management. While much research has already considered stock market integration in the financial markets (Chan et al., 1997), management strategies for global firms (Birkinshaw et al., 1995), and international marketing strategies (Jain, 1989), research on cross-cultural consumer interest - when it is generated relative to a domestic market and how it develops over time - is of particular interest to marketers.

The objective of this research is to explore cultural integration across international markets. With rapid developments in globalization, technological advancements, and the instant spread of news, are consumers across the globe becoming more culturally integrated? In other words, are consumers across the globe interested in the same ideas, topics, and products as those in the United States? If this is the case, there are many relevant implications for marketing strategy in areas such as advertising, new product development, and international product launches/marketing. This follows the research on international product diffusion, or the study of when new products are being adopted in various geographic markets and at what level. Prior to purchase or adoption, consumer interest in the product must be present. Thus, when and at what level is consumer interest being generated in various markets? Does it vary by topic?

The diffusion patterns of new product sales over time have been widely researched in marketing (Bass, 1969; Van den Bulte, 2000). Diffusion across both domestic and foreign markets has been studied (Mahajan et al., 1990; Talukdar et al., 2002), with international marketing research in general becoming more important as markets become more globalized (Malhotra, 2010). More specifically, there has been recent focus on emerging markets (Talukdar et al., 2002), as many markets in the United States are approaching saturation (Malhotra, 2010). Technological advancements have allowed for the measurement of consumer interest in new products prior to the availability of sales data. One example of such a measure is the volume of terms submitted to search engines. In other words, the volume of a particular search term can serve as an aggregate indicator of consumer interest in that particular term (Ettredge et al., 2005). This measure is available prior to the launch of a product, since a product 
need not be available to consumers for them to search for it. Thus, the patterns of consumer interest can be studied prior to the launch of a product. In one study, researchers used the pre-launch search term volume for movie titles to predict the opening-weekend box-office revenues of movies (Kulkarni et al., 2012). Since this online measure of consumer interest is not restricted by geographic boundaries, the patterns of consumer interest across international markets can also be investigated. These data will help marketers to develop better marketing strategies. While American strategy may work well in some foreign markets, it may not work as well in others. Findings from the study of the patterns of consumer interest can offer insight on the future diffusion of product sales and can also aid in managerial decision making on the timing of international product launches and other areas of marketing strategy. Thus, our research study aims to address the research question: (1) to what extent are consumers across developed and emerging international markets culturally integrating with the US?

\section{LITERATURE}

New product diffusion, or the adoption of a new product by a market, has been extensively researched in marketing for quite some time, with particular attention being given to quantitative models of diffusion. Much research has followed up on the classic Bass Model (Bass, 1969), which considers the timing of initial purchases of new products for consumer durables. The model is able to effectively predict the level and timing of peak sales as well as develop long-run forecasts of sales. Follow-up research on the Bass Model has generalized its empirical results and managerial implications to various supply and demand conditions (Mahajan et al., 1990; 1995) and looked at successive generations of high-technology products (Norton and Bass, 1987). More recent research has considered economic conditions and demographic changes in the market in relation to the speed of new product diffusion (Van den Bulte, 2000). The diffusion of innovative products specifically have also been studied (Swan, 1973; Milner, 2003). Although the objective of our research is not to model sales of new products but rather study patterns of consumer interest, many of the methods and theories employed in the research on sales diffusion across international markets can be applied to research on diffusion of consumer interest.

When considering the consumer decision-making process, interest is generated prior to a purchase being made. The decision-making process can be described as need recognition, information search, evaluation of alternatives, purchase decision, and post-purchase behavior (Armstrong and Kotler, 2011). Consumers will search for information when they have interest in a given product or topic. Thus, by studying the patterns of consumer interest, we are able to study consumers in earlier decision-making stages. By studying consumer interest patterns for various topics, we can study the degree of cultural integration between two markets. A closely aligned pattern of search indicates a similar pattern of consumer interest, which in turn indicates a high level of cultural integration.

While much of the research on new product diffusion has focused on markets within the United States, diffusion across international markets has also been addressed in the literature (Takada and Jain, 1991). Various economic and cultural factors and their influences on the rates of new product diffusion have been investigated. Some economic factors that have been considered are aggregate production and transportation, health, trade, lifestyle, and cosmopolitanism (Helsen et al., 1993). Cultural factors such as power distance, individualism, uncertainly avoidance, and masculinity have also been explored in the context of new product acceptance in foreign markets (Yeniyurt and Townsend, 2003). Country innovativeness is also a factor that has received much attention in the literature on international new product diffusion (Tellis et al., 2003). Of specific relevance to our study, comparisons of new product diffusion in developed and emerging economies have also been done (Talukdar et al., 2002). This study finds that emerging markets typically experience slower adoption rates than developed markets. The authors point out that much of the research on diffusion focuses on industrialized international markets and cannot be generalized to developing markets (Talukdar et al., 2002). Thus, the focus of our research is to compare patterns of consumer interest across developed and emerging markets. Many of the factors that have been previously studied in the context of international product sales diffusion will also be relevant to consumer interest. Similar patterns of consumer interest between two markets can indicate cultural integration between those markets.

In this study, we focus on Hofstede's cultural dimensions of power distance, individualism, masculinity, uncertainty avoidance, and long-term orientation (Hofstede, 1991). These dimensions are indexed from 0-100. Cultures with higher power distance indices are more comfortable with unequal power distributions. Cultures with large populations tend to have higher power distance, as well as cultures with highly unequal distributions of wealth. 
High individualism cultures rely on and have more allegiance to self rather than a group. High levels of individualism are usually found in wealthier and economically developed cultures. In general, a negative correlation tends to exist between a culture's power distance and individualism scores. Highly masculine cultures value assertiveness, achievement, and ambition. They also tend to have distinct expectations of gender roles. High uncertainty avoidance cultures tend to avoid ambiguity and uncertainty and prefer structure and formal rules. Lastly, cultures with higher indices of long-term orientation tend to value thrift, perseverance, having a sense of shame, and following a hierarchy. While we are not formally investigating the impact of culture or of specific dimensions of culture, we aim to use these indices of culture to possibly explain the differences in patterns of consumer interest we find across various countries. The following tables present the cultural dimensions for each of the countries in our study (Hofstede, 1991):

Table 1: Cultural Indices for USA and Developed Markets

\begin{tabular}{|l|c|c|c|c|c|}
\hline & USA & Australia & Canada & Germany & UK \\
\hline PowerDistance & 40 & 36 & 39 & 35 & 35 \\
\hline Individualism & 91 & 90 & 80 & 67 & 89 \\
\hline Masculinity & 62 & 61 & 52 & 66 & 66 \\
\hline UncertaintyAvoidance & 46 & 51 & 48 & 65 & 35 \\
\hline LongTerm Orientation & 29 & 31 & 23 & 31 & 25 \\
\hline
\end{tabular}

Table 2: Cultural Indices for USA and Emerging Markets

\begin{tabular}{|l|c|c|c|c|c|}
\hline & USA & Brazil & China & India & Russia \\
\hline PowerDistance & 40 & 69 & 80 & 77 & 93 \\
\hline Individualism & 91 & 38 & 20 & 48 & 39 \\
\hline Masculinity & 62 & 49 & 66 & 56 & 36 \\
\hline UncertaintyAvoidance & 46 & 76 & 30 & 40 & 95 \\
\hline LongTerm Orientation & 29 & 65 & 118 & 61 & NA \\
\hline
\end{tabular}

We choose developed markets as countries with large English-speaking populations across different continents - Australia, Canada, Germany, and UK. For the emerging markets, we choose the BRIC nations - Brazil, Russia, India, and China. We can see some interesting patterns. In general, emerging markets tend to have higher levels of power distance. As noted earlier, these markets also tend to have large populations and unequal distributions of wealth. Developed markets tend to be more individualistic. We don't see any clear patterns of masculinity or uncertainty avoidance across developed and emerging markets. Emerging markets tend to have more of a long-term orientation. Germany appears to differ from the US on dimensions of individualism and uncertainty avoidance to a greater extent than the other developed markets. Interestingly, China and India are quite similar to the US on the masculinity dimension as compared to the other emerging markets.

In this work, we consider a technology-based measure of cultural integration. Consumer interest in products has been measured using various metrics. One such metric is search engine keyword volume (Kulkarni et al., 2012). Since the submission of a term to a search engine requires an action on the part of the consumer, it can be inferred that the overall volume of a term submitted to a search engine indicates aggregate interest in that term. Prior research has found that the volume of search terms about a product can effectively predict sales of that product (Kulkarni et al., 2012). Prior research in a macroeconomic context has also found that the volume of search terms related to job searching (resume, job hunt) can be used to effectively predict the unemployment rate (Ettredge et al., 2005). Since our research aims to study the diffusion of consumer interest across international markets, and search engines are widely used internationally (Jansen and Spink, 2006), search term volume for products will serve as an effective measure of consumer interest. 
Our research study builds on and contributes to the literature on new product diffusion, international product diffusion, online search metrics, and consumer interest. From a practical standpoint, findings from the study will be beneficial to decision-making on international product launches and will aid new product sales forecasting. The results will also offer insight on factors that influence foreign interest in American products, concepts, and ideas, and will highlight differences across developed and emerging markets.

\section{DATA AND METHODOLOGY}

Our research methodology involves three main steps. First, we must identify what the American market is most interested in. Second, we must collect the search term volume data for these terms/topics (our measure of consumer interest) for the US, as well as each of the foreign markets of interest. Third, we must correlate the search data between the US and each of the foreign markets for each of the terms. We describe each of these steps in detail below.

First, given our research objective of comparing patterns of consumer interest in the US and international markets, we begin with the topics that US consumers were most interested in the calendar year 2010. Google Zeitgeist provides the ten fastest-rising queries for google.com. These ten terms are (Google Zeitgeist, 2010):

$\begin{array}{ll}\text { 1. } & \text { ipad } \\ 2 . & \text { chatroulette } \\ 3 . & \text { iphone } 4 \\ 4 . & \text { world cup } \\ 5 . & \text { justin bieber } \\ 6 . & \text { myxer } \\ 7 . & \text { facebook } \\ 8 . & \text { grooveshark } \\ 9 . & \text { glee } \\ 10 . & \text { mocospace }\end{array}$

These terms reflect a variety of interests in the US and refer to products having to do with social networking/communication tools, international events, popular culture, online music/media, and technology. We describe each of the terms in more detail. Ipad and Iphone 4 are high-technology products manufactured by Apple Inc. The Ipad is a touch screen tablet which was originally launched in 2010, and the Iphone 4 is a smart mobile phone. Chatroulette and Facebook are social networking tools. Chatroulette allows users to video chat with other users around the world at random. Facebook is an internationally popular online social network. The World Cup is an international soccer/football tournament that takes place every four years, with the most recent having taken place in 2010. Justin Bieber is a Canadian pop music star. Myxer is an online service that allows users to personalize mobile devices by uploading and downloading various media. Grooveshark is an online music service that allows users to search for and stream music. Glee is a popular American musical television show. Lastly, Mocospace is social networking tool for mobile devices.

Next, we take these ten terms and collect the weekly search data for each term for the US, as well as for each of the foreign countries in our dataset. Again, the developed markets we consider are Australia, Canada, Germany, and the United Kingdom. The emerging markets we consider are the BRIC nations: Brazil, Russia, India, and China. The online search data which serves as our measure of consumer interest is obtained through Google Insights for Search. This service allows search term volume for any search term to be collected for specific geographic areas and for specific time periods. We collect the data at the weekly level for the US and for each of the eight other international markets. The search term volume data is indexed on a scale ranging from $0-100$, where a measure of 100 indicates the peak number of searches for the given search term for the specified time period calendar year 2010 for the purpose of this study. The data is normalized to allow for comparison across geographic markets and is available in downloadable format (Google Insights for Search, 2011). "Just because two regions show the same percentage for a particular term doesn't mean that their absolute search volumes are the same. Data from these two regions - with significant differences in search volumes - can be compared equally because the data has been normalized by the total traffic from each respective region..." (Google Insights for Search Help, 
2011). In other words, if a particular term has equal indices across two regions, we can conclude that users from those two regions are equally likely to search for that term.

Google Insights for Search allows for comparisons to be made across five regions at one time. Thus, we conduct our analyses in two parts. First, we compare the US to the four other developed countries. Next, we compare the US to the four emerging countries. Thus, it would not be appropriate to compare the indices of Canada to India in our study, as the data is not normalized to allow for this, given our data collection procedure.

In our dataset, we have 52 data points (weekly in 2010) per search term (ten terms) per country (9 total countries). Lastly, we obtain the Pearson correlation coefficient for the weekly data points between the US and each of the eight foreign countries for each of the ten search terms (Kulkarni, 2011). We present and discuss our results in the next section.

\section{RESULTS AND DISCUSSION}

We calculate Pearson correlation coefficients for each of the terms. We are not able to obtain enough search data for the terms myxer and mocospace for all of the countries, so we remove these two terms from our analysis and proceed with the remaining eight terms. The correlation coefficients are presented in the following tables:

Table 3: Correlation Coefficients for USA and Developed Markets

\begin{tabular}{|l|c|c|c|c|}
\hline & Australia & Canada & Germany & UK \\
\hline ipad & 0.803 & 0.926 & 0.888 & 0.837 \\
chatroulette & 0.899 & 0.948 & 0.809 & 0.811 \\
\hline iphone 4 & 0.841 & 0.910 & 0.818 & 0.983 \\
\hline world cup & 0.992 & 0.997 & 0.979 & 0.976 \\
\hline justin bieber & 0.611 & 0.890 & 0.654 & 0.822 \\
\hline facebook & 0.708 & 0.924 & 0.977 & 0.782 \\
\hline grooveshark & 0.486 & 0.913 & 0.781 & 0.577 \\
\hline glee & 0.839 & 0.994 & 0.777 & 0.128 \\
\hline
\end{tabular}

*bold indicates significance at .05

Table 4: Correlation Coefficients for USA and Emerging Markets

\begin{tabular}{|l|c|c|c|c|}
\hline & Brazil & China & India & Russia \\
\hline ipad & 0.824 & 0.547 & 0.898 & 0.771 \\
chatroulette & 0.829 & 0.396 & 0.850 & 0.791 \\
\hline iphone 4 & $\mathbf{0 . 6 1 4}$ & 0.730 & $\mathbf{0 . 8 3 5}$ & $\mathbf{0 . 7 9 2}$ \\
\hline world cup & $\mathbf{0 . 9 1 7}$ & $\mathbf{0 . 9 8 8}$ & $\mathbf{0 . 9 2 1}$ & $\mathbf{0 . 9 8 6}$ \\
\hline justin bieber & $\mathbf{0 . 3 6 6}$ & $\mathbf{0 . 5 0 4}$ & $\mathbf{0 . 4 6 7}$ & $\mathbf{0 . 5 3 8}$ \\
facebook & $\mathbf{0 . 8 9 5}$ & $\mathbf{0 . 5 8 4}$ & $\mathbf{0 . 9 7 8}$ & $\mathbf{0 . 9 2 9}$ \\
\hline grooveshark & $\mathbf{0 . 7 7 3}$ & 0.254 & $\mathbf{0 . 5 2 4}$ & 0.186 \\
\hline glee & $\mathbf{0 . 7 0 1}$ & $\mathbf{0 . 8 1 7}$ & $\mathbf{0 . 3 0 5}$ & $\mathbf{0 . 8 3 2}$ \\
\hline
\end{tabular}

*bold indicates significance at .05 
From the above results, we can note some interesting patterns. Firstly, the patterns of search seem to be more similar to developed markets than emerging markets, in general. This is not surprising, since the developed markets in our study are predominantly English-speaking and more similar on cultural dimensions to the US.

We have two technology-related terms in our dataset, ipad and iphone 4. From the results, we can see that the correlations are high for all of the developed markets, as well as the emerging markets (though slightly lower), with India having the highest out of the emerging markets. This is not surprising, given India's recent boom in the technology sector. From a marketing perspective, these results may suggest that technology-based firms may benefit from simultaneous product launches in these markets.

We also have two social networking terms in our dataset - facebook and chatroulette. These correlations are also high for the developed markets and the emerging markets, with the exception of China. Similar marketing implications follow. China, where Facebook and other sites such as Twitter are blocked, may offer limited opportunity for social media marketers and social media firms from the US.

World cup, which relates to an international sporting event, has high correlations across all markets, which is not surprising given its international nature. Justin Bieber has the highest correlation with Canada, the closest market to the US in terms of geographic proximity. Market potential in further areas may be limited for products related to this pop star. The last two terms, also music-related, are grooveshark and glee. Grooveshark's correlation is also highest with Canada and not significant for China and Russia. Glee is highest for Canada as well and not significant for the UK.

In general, we see higher correlations with developed markets than with emerging markets. Earlier we saw that cultural dimensions are also more similar between the US and developed markets than the US and emerging markets, thus this result is not surprising. The highest correlations are with Canada and the lowest with China. International expansion for many firms may be fruitful in Canada and less so in China. India exhibits particularly high correlations for technology products and social networking, which is culturally intuitive. The remaining markets - both developed and emerging - fall somewhere in the middle. These results are not necessarily consistent with the results from the product diffusion literature which finds that emerging markets are slower to adopt new products (Talukdar et al., 2002). On the contrary, we find that consumer interest in many emerging markets is generated almost simultaneously with the US.

These results offer useful implications for marketing strategy. Intuitively, markets similar on cultural dimensions also seem to be similar in terms of consumer interest. Thus, marketing strategy in these markets can likely be more similar to strategy in the US. For example, marketing efforts related to popular culture can likely be expanded to Canada similarly and simultaneously. High-technology firms and social media marketers may benefit by launching and promoting products in India simultaneously rather than sequentially. More generally, these results suggest the importance of monitoring the patterns of consumer interest in foreign markets. While we do not link search data to marketing efforts or sales data in this research, we take a first step in examining cultural integration across international markets using an established online indicator of consumer interest. We discuss possible future extensions of this work on the next section.

\section{LIMITATIONS AND DIRECTIONS FOR FUTURE RESEARCH}

While the current study provides an exploratory analysis of cross-cultural patterns of consumer interest, there remain several areas for future research. Firstly, a more rigorous approach to understanding the impact of cultural factors on consumer interest could be taken. Modeling approaches, such as the ones in the new product diffusion literature, could be applied to search patterns over time (Talukdar et al., 2002). The reverse relationship could also be explored. In other words, how interested are Americans in topics of interest in foreign markets (Kulkarni, 2011)? Lastly, the relationship between search patterns and sales patterns for international markets could also be examined.

The primary limitation of the study is in the data sample. We consider not only Internet users, but Google users specifically. Generalizability to non-Internet users or users of other search engines may be limited. 


\section{AUTHOR INFORMATION}

Gauri Kulkarni is Assistant Professor of Marketing at the Sellinger School of Business and Management, Loyola University Maryland in Baltimore, MD. Her current stream of research focuses on consumer information search both online and offline. She considers online search as a predictor of new product sales and has developed forecasting models in this area. She has also studied the impact of search channel on consumer choice. She has recently expanded her research stream to an international domain and has studied patterns of consumer interest as measured by online search data across foreign markets. The current research was funded by a summer research grant from the Sellinger School of Business and Management. E-mail: gmkulkarni @ loyola.edu

\section{REFERENCES}

1. Armstrong, G., \& Kotler, P. (2011). Marketing: an introduction $\left(10^{\text {th }}\right.$ edition). Upper Saddle River NJ, USA: Prentice Hall.

2. Bass, F. M. (1969). A new product growth model for consumer durables. Management Science, 15(5), 215227.

3. Birkinshaw, J., Morrison, A., \& Hulland, J. (1995). Structural and competitive determinants of a global integration strategy. Strategic Management Journal, 16(8), 637-655.

4. Bulte, C. V. d. (2000). New product diffusion acceleration: Measurement and analysis. Marketing Science, 19(4), 366-380.

5. Chan, K. C., Gup, B. E., \& Pan, M.-S. (1997). International stock market efficiency and integration: A study of eighteen nations. Journal of Business Finance and Accounting, 24(6), 803-813.

6. Ettredge, M., Gerdes, J., \& Karuga, G. (2005). Using web-based search data to predict macroeconomic statistics. Communications of the ACM, 48(11), 87-92.

7. Google Insights for Search (2011), available at: http://www.google.com/support/insights/bin/topic.py?hl=en\&topic=13973

8. Google Zeitgeist (2010), available at: http://www.google.com/intl/en/press/zeitgeist2010/

9. Helsen, K., Jedidi, K., \& DeSarbo, W. S. (1993, October). A new approach to country segmentation utilizing multinational diffusion patterns. Journal of Marketing, 57(4), 60-71.

10. Hofstede, G. H. (1991). Cultures and organizations: Software of the mind. London, UK: McGraw-Hill.

11. Jain, S. C. (1989, January). Standardization of international marketing strategy: Some research hypotheses. Journal of Marketing, 53(1), 70-79.

12. Jansen, B. J., \& Spink, A. (2006). How are we searching the world wide web? A comparison of nine search engine logs. Information Processing and Management, 42(1), 248-263.

13. Kulkarni, G. (2011). Cross-Cultural Consumer Convergence as Indicated by Online Search Data. Nitte Management Review, 5(1), 1-10.

14. Kulkarni, G., Kannan, P. K., \& Moe, W. (2012). Using Online Search Data to Forecast New Product Sales. Decision Support Systems, 52(3), 604-611.

15. Mahajan, V., Muller, E., \& Bass, F. M. (1990). New product diffusion models in marketing: A review and directions for research. Journal of Marketing, 54(January), 1-26.

16. Mahajan, V., Muller, E., \& Bass, F. M. (1995). Diffusion of new products: Empirical generalizations and managerial uses. Marketing Science, 14(3), G79-G88.

17. Malhotra, N. K. (2010). Marketing Research: An Applied Orientation, $6^{\text {th }}$ edition. Prentice Hall, Upper Saddle River NJ.

18. Milner, H. V. (2003). "The Global Spread of the Internet: The Role of International Diffusion Pressures in Technology Adoption." Columbia University, working paper.

19. Norton, J. A., \& Bass, F. M. (1987). A diffusion theory model of adoption and substitution for successive generations of high-technology products. Management Science, 33(9), 1069-1086.

20. Swan, P. L. (1973, April). The international diffusion of an innovation. The Journal of Industrial Economics, 22(1), 61-69.

21. Takada, H., \& Jain, D. (1991). Cross-national analysis of diffusion in consumer durable goods in Pacific rim countries. Journal of Marketing, 55(2), 48-54.

22. Talukdar, D., Sudhir, K., \& Ainslie, A. (2002). Investigating new product diffusion across products and countries. Marketing Science, 21(1), 97-114. 
23. Tellis, G. J., Stremersch, S., \& Yin, E. (2003). The international takeoff of new products: The role of economics, culture, and country innovativeness. Marketing Science, 22(2), 188-208.

24. Yeniyurt, S., \& Townsend, J. D. (2003). Does culture explain acceptance of new products in a country?: An empirical investigation. International Marketing Review, 20(4), 377-396.

\section{NOTES}

